\title{
PLANNING, DESIGN AND IMPLEMENTATION OF THE ENHANCING CHILD NUTRITION THROUGH ANIMAL SOURCE FOOD MANAGEMENT (ENAM) PROJECT
}

\section{Colecraft EK* ${ }^{1}$, Marquis GS ${ }^{2}$, Sakyi-Dawson $\mathbf{O}^{3}$, Lartey $\mathbf{A}^{\mathbf{1}}$, Butler $\mathbf{L M}^{4}$, Ahunu $\mathbf{B}^{3}$,} Reddy $\mathrm{MB}^{5}$, Jensen $\mathrm{HH}^{6}$, Huff-Lonergan $\mathrm{E}^{7}$ and $\mathrm{E} \mathrm{Canacoo}^{3}$

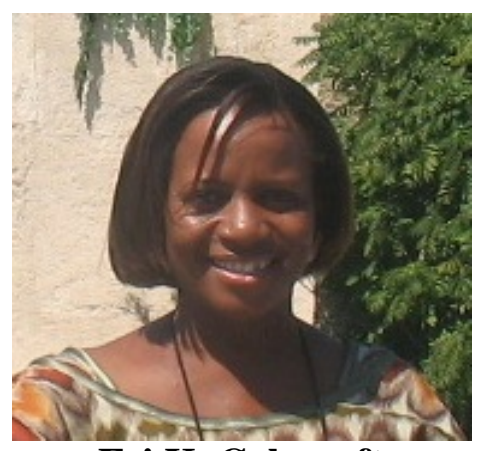

\section{Esi K. Colecraft}

*Corresponding author email: ecolecraft@ug.edu.gh

${ }^{1}$ Dept of Nutrition and Food Science, P.O. Box LG 134, University of Ghana, Legon, Ghana.

${ }^{2}$ School of Dietetics and Human Nutrition, McGill University, Quebec, Canada. ${ }^{3}$ College of Agriculture and Consumer Sciences, University of Ghana, Legon, Ghana.

${ }^{4}$ Global Agriculture and Life Sciences Fellow, Professor Emeritus (Iowa State University), 1215 Readings Drive, North Saanich, BCV8L5L2.

${ }^{5}$ Department of Food Science and Human Nutrition, Iowa State University, Ames USA

${ }^{6}$ Department of Economics, Iowa State University, Ames USA

${ }^{7}$ Department of Animal Science, Iowa State University, Ames USA 


\section{ABSTRACT}

The Global-Livestock Collaborative Research Support Program's (GL-CRSP) Child Nutrition Project, a controlled feeding trial in rural Kenya, demonstrated the importance of Animal Source Foods (ASF) for children's micronutrient status and cognitive development. These findings prompted research efforts to understand the constraints to ASF in children's diets in Africa so as to design targeted interventions to improve the ASF quality of children's diets. The Enhancing Child Nutrition through Animal Source Management (ENAM) project (2004-2009) emanated from participatory formative research that identified six principal constraints to the inclusion of Animal Source Foods (ASF) in children's diets in Ghana, including low income of caregivers, poor producer-consumer linkages, inadequate nutrition knowledge and skills of extension staff and caregivers, cultural beliefs, and inequitable household food distribution. To address these constraints, the ENAM project undertook a multidisciplinary community development, research and capacity building initiative with the goal of augmenting caregivers' access to and use of ASF in children's diets. Participatory processes were used to implement an integrated microcredit, entrepreneurship and nutrition education intervention with 181 caregivers of children 2- to5-years old in six rural communities across three agro-ecological zones (Guinea Savannah, Forest-Savannah Transitional and Coastal Savannah) of Ghana. Six matched communities from the same ecological zones served as comparison sites. Quantitative methods that included surveys, child anthropometry, and dietary assessment as well as qualitative case studies were used to assess the effect of the intervention on household, caregiver and child outcomes of interest. This paper presents the key features of the planning, design and implementation of the community intervention and the research processes undertaken to assess the project's impacts. The ENAM project model presents a unique approach for addressing caregivers' income and knowledge barriers to improve child nutrition in rural Ghana and may be a promising intervention model for scale-up in Ghana and other African countries.

Key words: Microcredit, Intervention, Animal source foods 


\section{INTRODUCTION}

The Global-Livestock Collaborative Research Support Program’s (GL-CRSP) Child Nutrition Project, a controlled feeding trial in rural Kenya, assessed the effects of animal source foods (ASF) intake on children's cognitive, nutrition, and health outcomes [1]. Twelve primary schools were randomly assigned to provide children with a daily isocaloric meal containing meat, milk or only vegetables. At the end of the 12-month feeding period, the children who received snacks with ASF showed significant improvements in micronutrient intake [2] and performed better on cognitive tests [3] compared to children who received only vegetables. These results unequivocally demonstrated the nutritional importance of ASF for children. Consequently, the GL-CRSP issued a two-stage request for proposals to identify constraints to the use of ASF in children's diets and to develop interventions to increase children's ASF intakes in sub-Saharan Africa.

Commonly reported reasons for low intakes of ASF among different household members in developing countries include financial constraints [4], discriminatory household food allocation practices [5] and dietary taboos [6]. In a review of the socio-cultural and household factors that influence ASF consumption, Gittelsohn and Vastine [7] discussed approaches for enhancing ASF intakes among household members. The authors stressed that an understanding of the cultural context in which an intervention will be applied is critical for making decisions about the best approaches to improving children's ASF intakes in a community. The study recommended using participatory mechanisms to foster community involvement in the design of culturally appropriate interventions to address community health concerns.

In 2003, the GL-CRSP supported a planning grant partnership between Iowa State University and the University of Ghana to carry out a multidisciplinary assessment and development of a context-specific problem model for understanding the causal links to low ASF intake among young children. The assessment methodology and outcomes (problem model and intervention priorities) have previously been described [8]. Briefly, the assessment encompassed participatory qualitative data collection and stakeholder consensus-building processes. The qualitative data collection had two key elements: (i) participatory rapid appraisal in six rural communities across three agro-ecological zones of Ghana during which caregivers of preschool aged children and community residents shared their perceptions about factors that hinder optimal child feeding and use of ASF in children's diets; and (ii) key informant and focus group discussions with program managers and frontline staff of health, nutrition and agriculture-based governmental and non-governmental institutions for their perspectives on the constraints to ASF availability, accessibility and utilization in children's diets as well as challenges to improve nutrition and well being in general in their operational areas.

The qualitative data provided useful insights into household food acquisition and allocation practices that had a bearing on children's ASF intakes in the targeted rural communities. For example, women in farming communities reported that women 
were responsible for the ingredients for the soups and sauces (which may include ASF), while men provided the accompanying staples (such as maize, cassava) for the household meal. Since home-reared animals were reserved for special occasions or as an emergency income source, ASF for family meals were typically purchased by women. Therefore, women's income was a limiting factor for household ASF consumption. Also, it was noted from discussions with caregivers and nutrition extension workers that there were few entrenched child-related ASF prohibitions in the communities but caregivers acknowledged that they prioritized adult males when allocating ASF in family meals. Caregivers generally stated that children would be served ASF if there were sufficient quantities of ASF; however, this was rare because caregivers' low income allowed for only small quantities of ASF to be purchased if at all. Caregivers were unable to increase their income with supplementary income generation activities due to a lack of capital.

Following the qualitative assessment, a stakeholder consensus building workshop was organized to: (i) validate the qualitative findings, (ii) collectively pool together the diverse perspectives on the constraints to children's ASF intakes into a holistic problem model, and (iii) recommend intervention priorities for addressing the constraints. The stakeholders included representatives from the communities, health, nutrition and agriculture-based governmental and non-governmental institutions, ASF-related trade associations (for example, the canoe fishermen's association and poultry farmers' association), as well as university researchers.

The resultant problem model from the participatory assessment process identified six principal constraints to the availability, accessibility and utilization of ASF in children's diets in Ghana. These constraints were: low caregiver income, poor producer-consumer linkages, inadequate ASF processing and storage facilities, inadequate knowledge and skills of frontline staff and caregivers, low caregiver empowerment and inequitable household food allocation practices, and cultural beliefs and attitudes. Stakeholders prioritized three interventions to mitigate these constraints: (i) financial, educational, and technical support for caregivers' IGA, (ii) caregiver education on the benefits of ASF for young children, and (iii) capacity building opportunities for current and future health, nutrition and agriculture-based extension practitioners. The problem model and recommended interventions are summarized in Figure 1. 

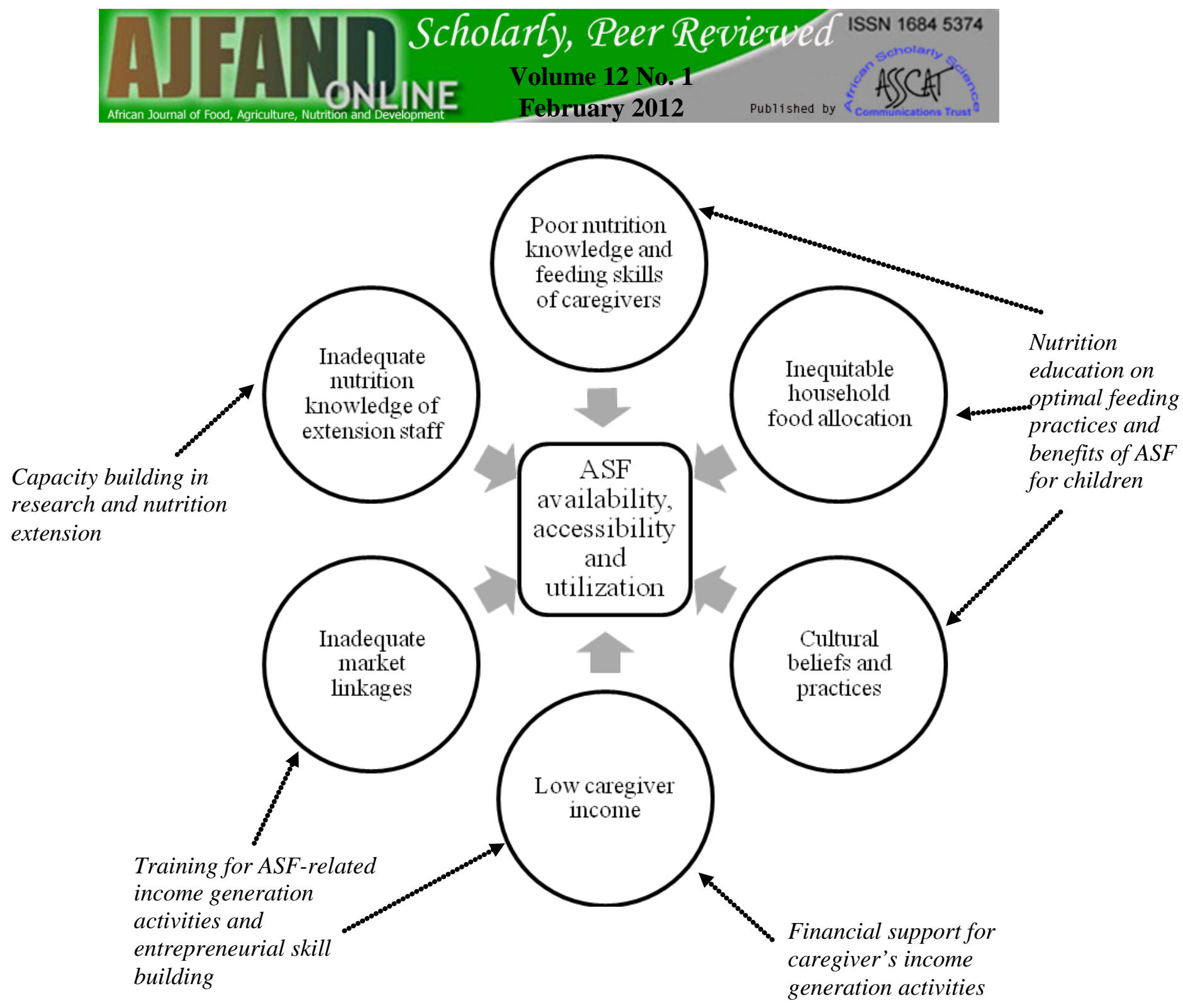

Italics: Interventions recommended by stakeholders to address specific constraints in the problem model

Figure 1: Problem model for the constraints to the availability, accessibility and utilization of ASF in children's diets in selected rural communities in Ghana and recommended interventions

\section{OBJECTIVES OF THE ENAM PROJECT (2004-2009)}

The problem model for constraints to ASF in children's diets was used to set objectives and design the interventions of the Enhancing Child Nutrition through Animal Source Food Management (ENAM) project. An integrated community development, research, and capacity building model that incorporated stakeholder recommendations to mitigate constraints to ASF in children's diets in Ghana was adopted. The overall goal of the ENAM project was to address caregivers' income and knowledge barriers to optimal child feeding with emphasis on increasing the 
quantity and diversity of ASF in children's meals. The three components of the project were guided by the specific objectives and research questions summarized in Table 1. In this paper, we detail the planning and implementation of the community development interventions as well as the design and data collection processes associated with the research component of the project.

\section{MATERIALS AND METHODS}

\section{Study sites}

In consultation with the Ministry of Food and Agriculture, two communities (one rural and one semi-rural) were selected from each of three ecological zones in Ghana specifically (Figure 2), the Guinea Savannah (GSZ), Forest-Savannah Transitional(FSTZ), and Coastal Savannah (CSZ) zones [8]. These ecological zones were purposively selected to reflect the diversity of ASF across the country. For each of the six intervention communities, a corresponding comparison community was selected in the same administrative district with similar characteristics with respect to livelihoods, infrastructure, size and perceived wealth. Crop farming was the primary source of household income for both the intervention and control communities in the FSTZ, the GSZ, and the semi-rural communities of the CSZ. Fishing was the main occupation of men living in the rural community of the CSZ and was also an important source of income for men in the GSZ. The main occupation for the majority of CSZ women was smoking of or trading in fresh fish; in the GSZ, women also processed and retailed fish purchased from community fishermen (typically their spouses) at the dam. In all communities most women were engaged in a subsidiary income generation activity, typically petty trading. 


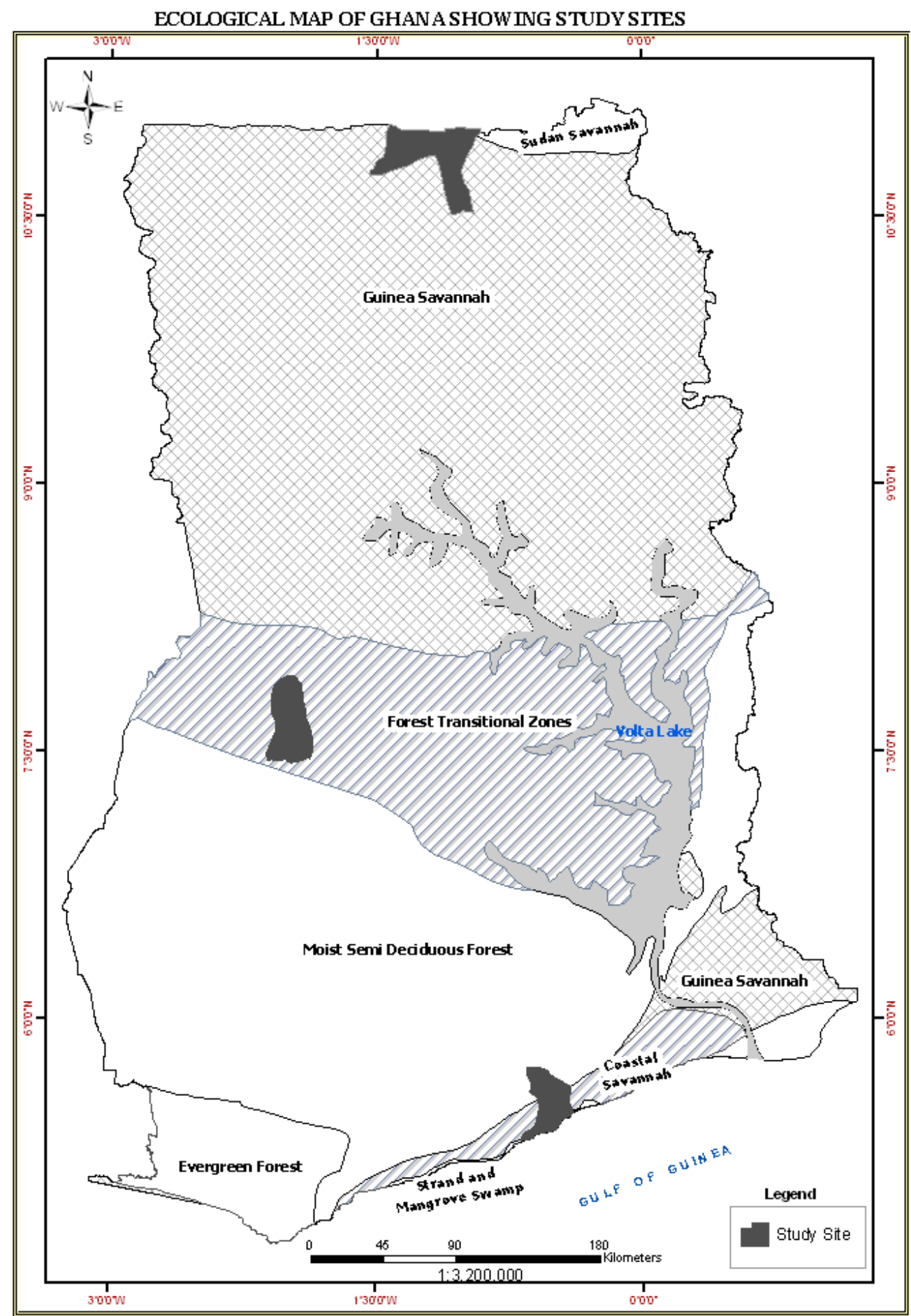

Figure 2: Map of Ghana showing study areas of the three agro-ecological zones included in the study 


\section{Planning and implementation of the community interventions}

A micro-credit scheme which comprised of financial (loans) and technical (capacity building in poultry rearing and fish smoking and entrepreneurship training) support for caregivers' income generation activities (IGA) combined with nutrition education, was implemented in the intervention communities. The target population was caregivers with children, aged 2 to 5years. For the purposes of this study, a caregiver was defined as the person responsible for caring for and feeding the child most of the time, based on self-report. The planning and implementation stages of the microcredit and education interventions involved several, sometimes overlapping steps. During the planning stage we: (i) explored best practices in financial support strategies used with women's groups in Ghana; (ii) trained Program Field Officers (PFO); (iii) fostered caregiver participation in ranking of the most appropriate IGA for their communities; (iv) assessed the viability of potential IGA; (v) designed financial support packages for selected IGA; and (vi) developed nutrition and entrepreneurial education materials. The implementation stage involved (i) IGA training and community sensitization about the microcredit and education intervention; (ii) formation of women's Credit and Savings Associations (CSA); (iii) initiation of loan cycle; and (iv) facilitation of weekly CSA meetings. Details of the processes associated with the planning and implementation stages are documented in the GLCRSP 2006 annual report [9] and are summarized below.

\section{Intervention planning}

1. Defining best practices in support strategies for caregivers' IGA: A qualitative assessment of 18 local, national and international organizations with experience in microcredit activities in Ghana was undertaken to determine the best practices associated with these programs [10]. Key features of successful microcredit activities included: (i) lending to individuals within groups with group members mutually guaranteeing each others' loans, (ii) spreading loan repayments over a pre-determined loan cycle (defined as the period starting when the loan is disbursed and ending when the loan is fully re-paid by all group members) with a meeting schedule for regular loan repayments, and (iii) requirements for weekly savings contribution with participants expected to accrue a specified percentage of the loan amount as savings by the end of the loan cycle. While improved food security and nutrition was a programmatic objective for almost all the microcredit programs reviewed, only 2 of the 18 organizations specifically incorporated nutrition education in their activities. Lessons learned from the 'best practices' assessment activity guided the design and implementation of the ENAM project microcredit scheme.

2. Training program field officers (PFO): A PFO was appointed for each study zone. The PFO assisted with preliminary intervention planning processes and facilitated implementation of the microcredit and education interventions in the communities. The three PFO received training in community mobilization, participatory appraisal processes and microfinance/microcredit principles. 
3. Identifying the most appropriate IGA: The PFO facilitated community-wide IGA identification and ranking processes in which interested caregivers collectively listed women's IGA that existed in the community as well as other IGA that they considered suitable for their communities. The activities were ranked by the women according to the following criteria: (i) availability of and access to needed inputs, (ii) access to markets, (iii) profitability and having a quick turnover, and (iv), potential for the IGA to influence child nutrition through inclusion of ASF in household meals. The highest ranked IGA included poultry production and petty trading (particularly in foodstuff) for all three study zones, retail of fresh or smoked fish for communities in the CSZ and GSZ, and production and commercialization of cosmetic products and tie/dye cloth for communities in the FSTZ.

4. Assessing the viability of ranked IGA: Trading in foodstuff, poultry production, fish smoking, retail of fresh fish, and trading in firewood were considered viable by the ENAM staff. Cash flow analysis was completed for each IGA to assess its profitability within the context of each intervention community. Based on the outcome of the cash flow analyses the most viable IGA were: fish smoking for communities in the CSZ and GSZ, poultry production for communities in the FSTZ and GSZ, and trading in foodstuffs for all communities.

5. Financial support packages for viable IGA: Due to differences in cost of inputs and expected revenues, different levels of financial support were needed for the IGA that were selected for promotion. For each IGA, a microcredit support package was developed that specified (in Ghana cedis) the maximum repayable loan, the grant (if any) to be provided by the project, and the required inputs to be provided by the participant.

6. Development of nutrition and entrepreneurial education materials: To facilitate delivery of the educational component of the intervention, a nutrition education flipchart [11] and entrepreneurship training manual were developed. The nutrition education flipchart was comprised of interactive lesson plans with associated illustrations designed to improve caregivers' understanding of the benefits of including ASF and diversifying young children's diets. Important young child feeding principles related to feeding frequency and responsive feeding, and hygiene were addressed. Prior to its implementation, the flipchart was field-tested for clarity and cultural appropriateness with caregivers of young children in non-ENAM communities across the three ecological zones. With stakeholder input, the flipchart was revised after one year of use, to enhance its utility beyond the ENAM project interventions. The revisions included replacing illustrations with real-life photos and addition of lesson plans on hand washing and street foods to address the significant consumption of ready-to-eat foods by children [12] and our observations of poor hand washing practices in the communities.

The entrepreneurship training manual provided caregivers with information and skills to improve their business management practices to enhance incomes from their IGA. Topics addressed included customer care, value addition and marketing principles with emphasis on product pricing and promotion. Each interactive lesson plan 
concluded with a slogan to reinforce key messages. In the third year of the project, the entrepreneurship education manual was adapted into a pictorial flipchart [13].

\section{Implementation}

1: Community-wide caregiver IGA training and microcredit sensitization: The PFO facilitated community-wide training in the selected IGA in the intervention communities. The training involved: (i) mentoring of interested caregivers by women already involved in the selected IGA; (ii) community-wide training in improved fishsmoking (in CSZ and GSZ); and (iii) community-wide training in poultry production (chickens in CSZ and FSTZ; guinea fowl in GSZ).

Community sensitization was achieved through interactive group discussions with caregivers on the objectives of the project and eligibility requirements for participation in the project's microcredit scheme. The eligibility criteria were: (i) caregiver of a child aged 2 to 5years, (ii) one caregiver-child pair per household, (iii) residence in the intervention community,(iv) willingness to undertake approved IGA, and (v) membership in the ENAM project Credit and Savings Association (CSA). To be a CSA member, caregivers were required to form solidarity groups (SG) of 3-5 women willing to mutually appraise and guarantee each other's loans. The CSA in each community constituted of 3-10 SG.

2. Forming community Credit and Savings Associations: In each intervention community the PFO facilitated self-selection of eligible caregivers into SG and the formation of the community CSA.

Each CSA elected leaders (president, treasurer, secretary, and organizer/porter) by ballot from the pool of SG members. Project regulations instituted for the CSA included: (i) loans provided to individuals within the CSA with SG members responsible for appraising and approving loan proposals submitted by their members prior to loan disbursement; (ii) SG members serve as mutual guarantors for members loans; (iii) loan repayment to be spread over a 16-week loan cycle (with successive loans to any CSA/SG member contingent on full repayment of the preceding loan by all members); (iv) compulsory weekly meeting attendance for loan repayment and participation in entrepreneurship training and nutrition education; (v) weekly savings deposits (requirement to save at least $20 \%$ of loan amount by end of loan cycle); and (vi) future loan increments dependent on satisfactory weekly meeting attendance (at least 70\%) and level of savings in the preceding loan cycle. CSA members developed their own additional by-laws to govern the group.

3. Initiation of loan cycle: The first loan cycle was initiated with disbursement of loans to CSA members occurring in May, July and August 2006 for the CSZ, FSTZ and GSZ communities, respectively. Caregivers invested in fish smoking and trading enterprises with the first loans dispersed (Table 2). Poultry activities were not initiated due to reported outbreak of bird flu in Ghana. In 2008, however, additional funding from USAID's Women in Development Office provided an opportunity to collaborate with Heifer Project International, Ghana to undertake more in-depth assessment of the 
potential for poultry production in the intervention communities. Based on the assessment, poultry production was not recommended for the CSZ because of limited interest by community members and limited access to inputs, especially feed ingredients. Chicken egg and guinea fowl production were subsequently initiated in the FSTZ and GSZ, respectively.

4. Facilitation of weekly CSA meeting: The PFO facilitated weekly CSA meetings. The meetings were structured as one-hour sessions with the first 15-20 minutes devoted to delivery of either an entrepreneurial or nutrition education session, followed by loan repayments and savings contributions by the CSA members. These activities were intermingled with ice-breakers (typically song and dance routines) to enhance caregiver participation and group cohesiveness. CSA secretaries logged caregiver attendance at weekly meetings in the attendance register and recorded repayments and savings deposits in the CSA members' individual accounts books as well as the project register. The PFO and CSA treasurer deposited all cash received at the weekly meetings in the ENAM project account at the local rural bank. The first cycle loans were fully recovered within 16 weeks for the CSZ and FSTZ community CSA and 21 weeks for the GSZ community CSA.

Prior to initiating the second loan cycle, each CSA was opened to new membership. Eligible caregivers wishing to become members could be adopted into existing SG or establish new ones. Solidarity Group members could approve or reject existing or new members to their group during the loan appraisal period. Loan amounts for new members could not exceed those previously established in the support packages for the recommended IGA. A returning caregiver who attended at least $70 \%$ of the weekly meetings and saved at least $20 \%$ of her initial loan amount in the preceding cycle was eligible for a $50 \%$ loan increment subject to appraisal and approval by her SG.

Subsequent loan cycles followed the same format however the CSA was closed to new membership at the end of the second cycle. Completion of the fourth loan cycle in each community marked the end of the ENAM project's active management of the community CSA. Education sessions were alternated between cycles; caregivers received only nutrition education during the first cycle and entrepreneurship training during the second loan cycle. Both nutrition and entrepreneurship education were provided during the third and fourth loan cycles.

\section{Research Design and Sample}

A quasi-experimental longitudinal design was adopted with intervention and control caregivers identified and selected according to the flow chart in Figure 2. With assistance from community key informants, a census of all households and caregivers with 2- to 5-years-old children was generated for each of the six intervention and six control communities. Community mapping and household wealth ranking exercises were completed using procedures described in Colecraft et al. [8]. A total of 652 and 561 households/caregivers with 2- to 5-years-old children were listed for the intervention and control communities, respectively. A baseline household survey was completed (between June and August 2005) with all caregivers who agreed to be 


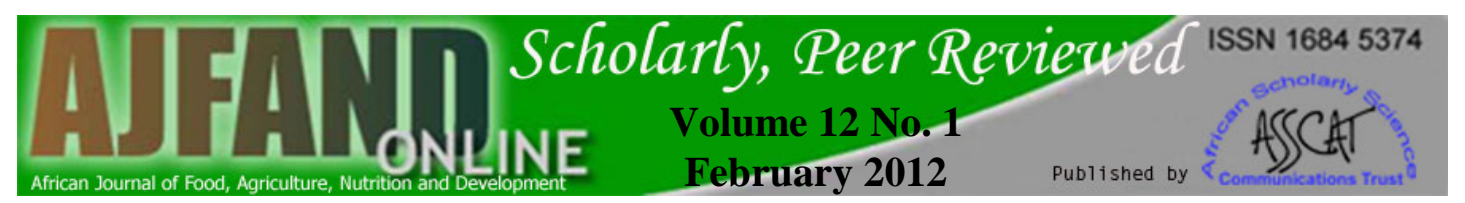

interviewed ( $\mathrm{N}=629$ from intervention communities and $\mathrm{N}=540$ from control communities).

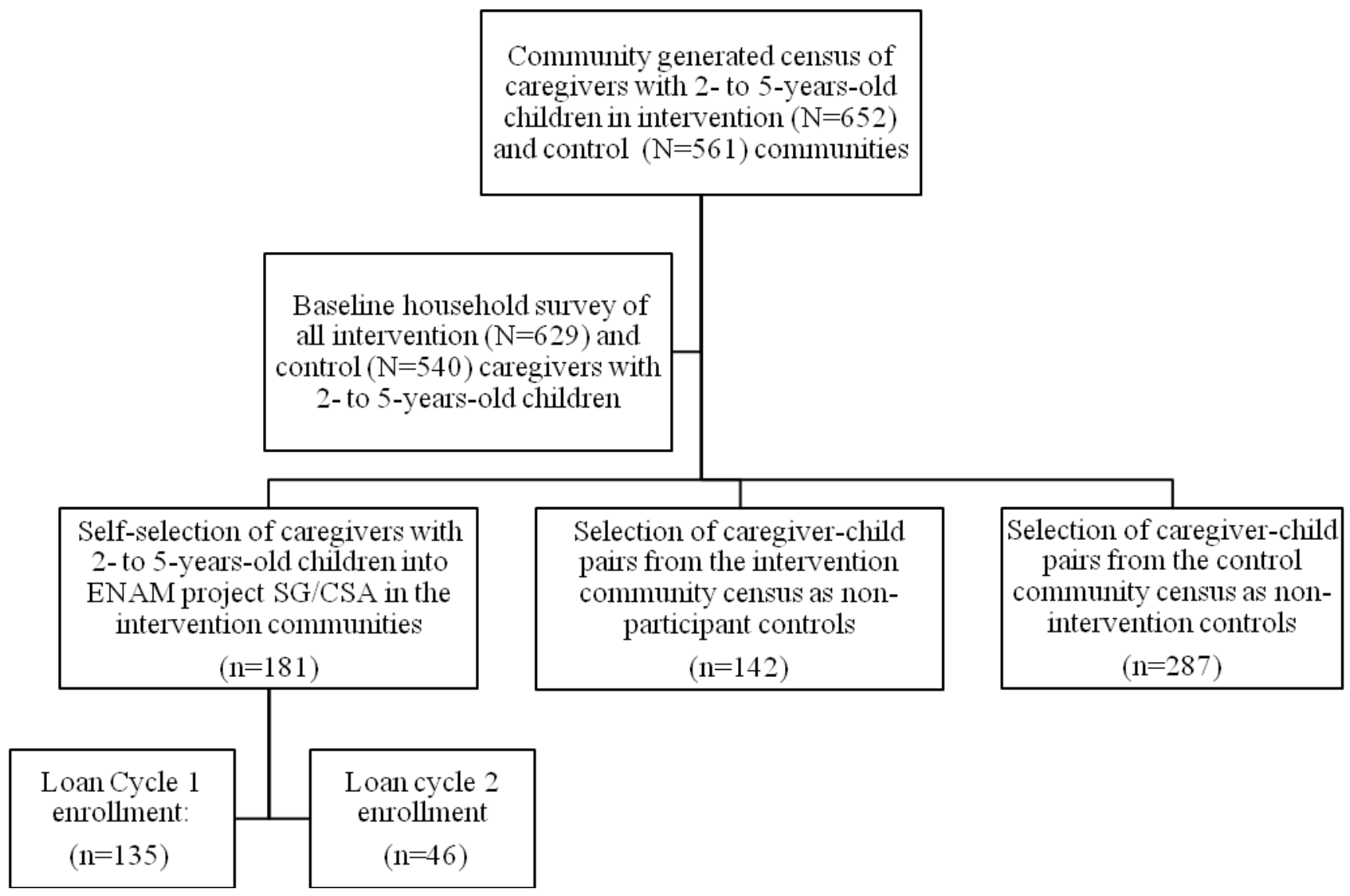

Figure 3: Flow chart of the ENAM project participant selection and sample sizes

Eligible caregivers were enrolled into the ENAM project's integrated microcredit and education program in the intervention communities subsequent to the baseline household survey. During two enrollment periods, corresponding to the start of the first $(\mathrm{N}=135)$ and second $(\mathrm{N}=46)$ loan cycles, a total of 181 caregivers with 2- to 5years-old children were self-selected into SG and membership in the ENAM project CSA in each intervention community. For each CSA member, 1 to 2 caregivers with similar household wealth rank and primary occupation was identified from the baseline household survey database for each community to serve as non-participant and non-intervention controls. Non-participant controls therefore were caregivers who lived in the intervention communities but were not members of the CSA while non-intervention controls were caregivers selected from the control communities that did not receive the microcredit intervention. 
The study was approved by the institutional review boards at Iowa State University, the Noguchi Memorial Institute for Medical Research at the University of Ghana, and McGill University. Written informed consent was obtained from all caregivers who agreed to participate in both the intervention and control communities. Permission to work in the communities was granted by the chiefs and other community leaders following community entry processes to introduce the study.

\section{Data collection}

A range of qualitative and quantitative data was collected over the lifespan of the project to facilitate intermediate process and end-of-project impact assessments. The key components were (i) pre- and post intervention household surveys, (ii) longitudinal survey and child anthropometric assessments, (iii) periodic in-depth dietary assessments, and (iv), cross-sectional case studies. The methodology adopted for the case studies has been described by Butler et al.[14] in this supplement.

Pre- and post-intervention community surveys: The baseline household survey was administered to all caregivers of 2- to 5-years-old children who agreed to participate in the intervention and control communities. The survey was repeated at the end of the project (at the completion of the fourth loan cycle) between January and February 2008. The household surveys provided information on the target population with respect to household demography, agricultural livelihoods and months of food shortage, household ASF consumption, and child-related ASF prohibitions.

Longitudinal surveys and child anthropometric assessments: A questionnaire instrument designed to enable comparisons between intervention and control caregivers and address the set research questions was used to interview intervention and control caregivers at baseline and up to four quarterly follow-up time points. Baseline data collection was undertaken from April to July 2006 for caregivers who enrolled in the six intervention community CSA at the start of the first loan cycle and their corresponding control caregivers and from November 2006 to February 2007 for caregivers enrolled at the start of the second loan cycle and their corresponding control caregivers. The final data collection time point was from September to November 2007. Thus, between baseline and the final data time point, four quarterly follow-up data collections were completed for the first loan cycle caregivers and their controls and three follow-up data collections were completed for the second loan cycle caregivers and their controls. Information solicited by the questionnaire included: (i) caregiver and household socio-demographic characteristics;(ii) ASF expenditures in the past week; (iii) household food frequency in the past week; (iv) children's ASF consumption in the past week; (v) caregivers' child-related nutrition and health knowledge; and(vi) household food and ASF security. Children's weights and heights were also recorded using standard procedures at each data collection time point [15].

Periodic in-depth dietary assessments: Two non-consecutive 12-hour home observations of children's dietary intakes were completed on cross-sectional subsamples of the intervention caregiver-child pairs and their controls during the first and third loan cycles and at the completion of the fourth loan cycle. At each time point,

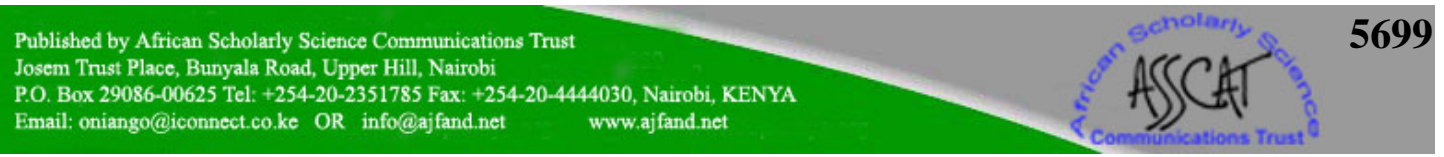


the 12-hour observations were completed on one working and one non-working day for the CSZ communities and one market and one non-market day for the FSTZ and GSZ communities. All foods and beverages consumed by the study child were weighed and recorded during the observation period. An observation checklist of caregivers' feeding practices was also completed for each eating event observed during the home visits. Caregivers were notified of the observation days within the week of the visit.

\section{Field data quality control}

Data collection activities were coordinated by the field supervisor who travelled to each field site prior to the start of each data collection period. With the assistance of the program field officer in each study zone, the field supervisor facilitated hiring and training of local field workers to assist with data collection. Minimum hiring requirements for field workers was completion of high school and fluency in English and the primary local language of the study area. Training of field workers entailed (i) review of interview tools such as questionnaires and reaching consensus on translation of questions/concepts in the local language; (ii) training in children's weight and height measurements using a Secca digital weighing scale and Shorrstadiometer, respectively, and (iii) training in food weighing using an electronic food balance for the in-depth dietary studies. Training sessions included role play with the data tools and practice sessions in non ENAM communities. On average, eight local field workers were hired and trained at each study zone during each data collection period. At least $50 \%$ of the local field workers hired during the baseline data collections were available to assist with the follow-up data collections.

During the data collection period, data forms completed in the communities were reviewed for completeness and accuracy at the end of each day with the project field supervisor and or the project field officer in each zone. Field workers with incomplete data forms returned to the respondents the following day to make the necessary changes. At the end of each data collection session, the data forms were sealed and transported to the ENAM project office in Accra where they were checked by two trained data entry clerks and entered into a database using SPSS version 16.0

\section{CONCLUSION}

Though requiring significant time and resource commitment, the attention given to ensuring participatory processes and knowledge generation with community and institutional stakeholders was the mainstay for successful implementation of the ENAM interventions. Preliminary data analysis showed that the intervention was successful in achieving the objectives of improving caregivers' child nutrition knowledge [16] and enhancing children's ASF intakes [17], additionally, project participants reported improved business practices and earnings and a savings culture, which previously did not exist, was inculcated among them.

Leatherman and Dunford [18] advocate for the integration of financial services and health to improve income security and health among the poor based on evidence of positive impacts from microfinance institutions delivering health education in 
conjunction with financial services. The ENAM project intervention model adds to the body of evidence that health-related behavior change among poor households is attainable when health-related educational messages are delivered with financial and entrepreneurship training services.

\section{Lessons Learned}

Application of the multiple processes and activities encompassed by the ENAM project methodology fostered useful learning experiences than can inform future efforts in integrated development and research programming. The factors that enabled effectual realization of the project objectives as well as challenges that emerged in the course of carrying out the various components of the project methodology are discussed.

\section{Enabling factors}

A key enabling influence for the successful implementation of the project methodology was the application of community mobilization principles in the planning and implementation of the project interventions. Community mobilization has been defined as a capacity building process through which community individuals, groups, or organizations carry out and evaluate activities on a participatory and sustained basis to improve their health and other needs [19]. This process was initiated in the preliminary problem model development phase and sustained through the planning and implementation stages of the project.

During the formative problem model development phase of the project, we engaged caregivers of young children and other community and institutional stakeholders to reflect on and evaluate the range of factors that influence child feeding practices relative to ASF. These interactions raised community awareness about the importance of young child nutrition, fostered collective analysis of the constraints to ASF in children's diets as well as ensured that the resultant problem model and associated solutions reflected stakeholders own conceptions. Consequently, a sense of community ownership of the interventions was nurtured in the formative stages of the project. Subsequent implementation of the ENAM project interventions in the same communities where the formative assessments were completed was in effect in response to community demand for the interventions and thus engendered community enthusiasm and commitment to the project activities.

Program field officers in each intervention community facilitated community-wide processes that enabled community individuals (caregivers of young children) to select appropriate income generation activities for their communities and to rank them according to child nutrition-related criteria. All business enterprises promoted in the communities had been identified by community individuals as appropriate for their communities and had been assessed to be lucrative. Thus the project activities served to enhance caregivers' capacities to expand, diversify, and manage enterprises they were familiar with, in more profitable ways.

Another enabling influence was the time given to learning from the experiences of existing financial and technical support programs for caregivers' income generation

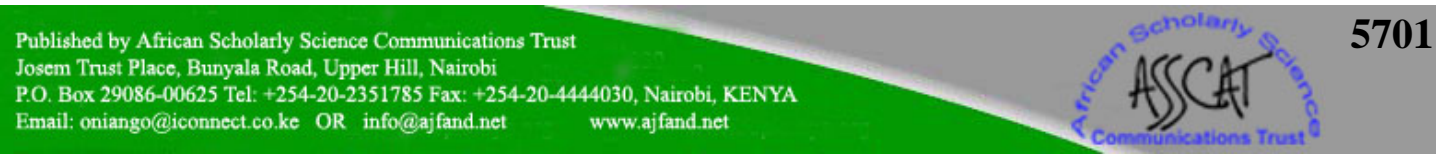


activities. Identifying and applying best practices and lessons learned from existing programs enabled us to adapt the best approaches in the design and implementation of the project's combined microcredit, entrepreneurship training and nutrition education program and avoid reinventing the wheel. Consequently the ENAM microcredit and education model was adapted from Freedom from Hunger's Credit with Education concept [20].

In summary, successful implementation of the ENAM model resulted from the time investment to ensure effective community involvement in the planning and implementation of the program. The planning grant process was a vital component of the methodology and speaks to the value of formative research for fostering community participation in the diagnosis of community nutrition problems and planning of context-specific interventions

\section{Challenges}

A major challenge faced was ensuring effective management of the multiple project components, often occurring concurrently, in multiple project sites. In this regard, the role of the project field officers in facilitating implementation of the community activities cannot be understated. While the dynamic and personal commitment of project field officers contributed to their effectiveness, significant investments were made in building their capacities to carry out the various aspects of the program which helped to deepen their understanding of the project activities and their own role in facilitating the activities. Routine process monitoring and data collection necessitated regular supervisory visits to the field which enhanced accountability and communication with the project's field officers and also contributed to effective management of the project.

A central component of the project intervention was the women's CSA. The group formation process was highly participatory with the women themselves deciding on who they accept into the group and choosing their own group leaders. These processes ensured that eventual sustainability of each CSA was built into the group formation process. However, many of the women were often reluctant to take up leadership roles in the CSA. The institution of a peer educator program which provided leadership coaching through training in the delivery of the project's educational materials was a useful tool for empowering those selected by their groups for the training to take ownership of the groups and lead.

Process monitoring of the CSA in all study areas, showed differences in caregivers' responses to the project interventions and demonstrated that 'one size does not fit all'. Even with the meticulous process undertaken to ensure promotion of the most viable IGA in each intervention area, the CSA members in communities that already had strong market systems were more productive than those in areas with limited market systems. Also, caregiver characteristics, as demonstrated by the case studies $[14,21]$ influenced how individual caregivers experienced the program. These are important issues to consider in efforts to adapt the ENAM methodology for different community contexts. 


\section{ACKNOWLEDGEMENTS}

This publication was made possible through support provided to the Global Livestock Collaborative Research Support Program by the Office of Agriculture, Bureau for Economic Growth, Agriculture and Trade, United States Agency for International Development under terms of Grant No. PCE-G-00-98-00036-00. The opinions expressed herein are those of the author(s) and do not necessarily reflect the views of the USAID. 
Table 1: The ENAM project's community development, research and capacity building objectives

\begin{tabular}{|c|c|c|}
\hline $\begin{array}{l}\text { Community development } \\
\text { objectives }\end{array}$ & Research Questions & Capacity building objectives \\
\hline $\begin{array}{l}\text { 1. Enhance caregivers' } \\
\text { purchasing power for } \\
\text { increased access to ASF } \\
\text { through provision of } \\
\text { financial and technical } \\
\text { support for caregivers' } \\
\text { income generation } \\
\text { activities (IGA) } \\
\text { 2. Increase caregivers' } \\
\text { knowledge about the } \\
\text { nutritional importance } \\
\text { of ASF for children } \\
\text { 3. Increase children's ASF } \\
\text { intakes by improving } \\
\text { caregivers' feeding } \\
\text { practices and skills for } \\
\text { incorporating ASF in } \\
\text { children's diets } \\
\text { 4. Improve child growth } \\
\text { through improved } \\
\text { caregiver feeding } \\
\text { practices }\end{array}$ & $\begin{array}{l}\text { Does a combined } \\
\text { microcredit, } \\
\text { entrepreneurship training } \\
\text { and education on the } \\
\text { benefits of ASF in children's } \\
\text { diets improve: } \\
\text { 1. Caregiver household } \\
\text { incomes? } \\
\text { 2. Caregivers' sense of } \\
\text { household food } \\
\text { security? } \\
\text { 3. Caregivers' expenditures } \\
\text { on ASF? } \\
\text { 4. Caregivers' knowledge } \\
\text { of ASF benefits? } \\
\text { 5. The quantity and } \\
\text { diversity of children's } \\
\text { ASF intakes? } \\
\text { 6. Children's physical } \\
\text { growth? }\end{array}$ & $\begin{array}{l}\text { 1. Provide research training } \\
\text { for local and international } \\
\text { masters level students } \\
\text { 2. contribute to pre-service } \\
\text { training in extension } \\
\text { principles of future } \\
\text { nutrition-based } \\
\text { practitioners through the } \\
\text { introduction of a nutrition, } \\
\text { livelihoods and extension } \\
\text { course into the } \\
\text { undergraduate curriculum } \\
\text { of the Nutrition and Food } \\
\text { Science Department at the } \\
\text { University of Ghana } \\
\text { 3. Provide current health, } \\
\text { nutrition and agriculture- } \\
\text { based practitioners } \\
\text { opportunities for sharing } \\
\text { experiences and learning } \\
\text { new information through } \\
\text { workshops } \\
\text { 4. Develop a non-degree } \\
\text { short course to provide } \\
\text { opportunities for current } \\
\text { practitioners to upgrade } \\
\text { their knowledge and skills } \\
\text { in nutrition extension. }\end{array}$ \\
\hline
\end{tabular}




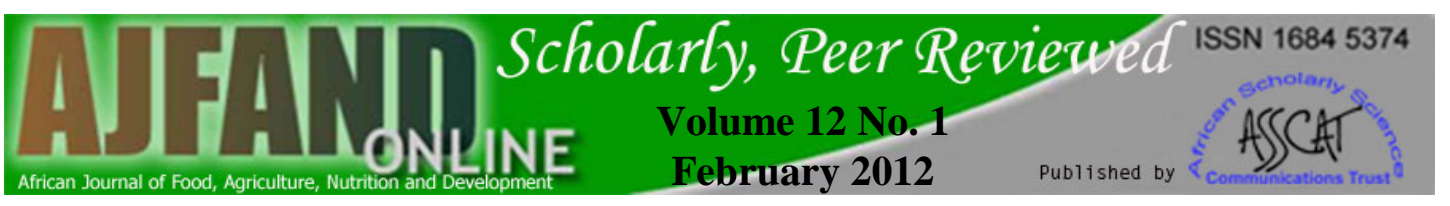

Table 2: Distribution of ENAM project CSA, caregivers' IGA and loans received in the first loan cycle

\begin{tabular}{|c|c|c|c|c|c|c|}
\hline \multirow[b]{2}{*}{$\begin{array}{l}\text { Location of } \\
\text { community CSA }\end{array}$} & \multirow{2}{*}{$\begin{array}{l}\text { Number of } \\
\text { solidarity } \\
\text { groups }\end{array}$} & \multirow{2}{*}{$\begin{array}{c}\text { Number of } \\
\text { caregivers } \\
(\mathrm{N}=135)\end{array}$} & \multicolumn{2}{|c|}{ Selected IGA } & \multicolumn{2}{|c|}{ Loan size (GHC) ${ }^{1}$} \\
\hline & & & $\begin{array}{l}\text { Fish } \\
\text { smoking }\end{array}$ & Trading & $<50$ & $\geq \mathbf{5 0}$ \\
\hline \multicolumn{7}{|c|}{ Coastal Savannah zone } \\
\hline Rural & 3 & 12 & 5 (39) & $8(61)$ & $2(15.4)$ & $11(84.6)$ \\
\hline Semi-rural & 4 & 15 & $3(20)$ & $12(80)$ & $4(26.7)$ & $11(73.3)$ \\
\hline \multicolumn{7}{|c|}{ Forest-Savannah Transitional zone } \\
\hline Rural & 7 & 26 & $0(0)$ & $26(100)$ & 7 (26.9) & $19(73.1)$ \\
\hline Semi-rural & 8 & 26 & $0(0)$ & $26(100)$ & $2(7.7)$ & $24(92.3)$ \\
\hline
\end{tabular}

Guinea Savannah zone

$\begin{array}{lcccccc}\text { Rural } & 8 & 24 & 10(42) & 14(58) & 32(100) & 0(0) \\ \text { Semi-rural } & 6 & 32 & 17(53) & 15(47) & 24(100) & 0(0)\end{array}$

${ }^{1} 1$ Ghana cedi $(\mathrm{GH} \mathbb{C})=$ US $\$ 1.00$ in 2008 


\section{REFERENCES}

1. Neumann C, Bwibo NO, Murphy SP, Sigman M, Whaley S, Allen LH, Guthrie D, Weiss RE, and $M$ Demment Animal source foods improve dietary quality, micronutrient status, growth and cognitive function in Kenyan school children: Background, study design and baseline findings. J. Nutr 2003; 133: 3941S-3949S.

2. Murphy SP, Gewa C, Liang L, Grillenberger M, Bwibo N, and CG Neumann School snacks containing animal source foods improve diet quality for children in rural Kenya. J. Nutr. 2003; 133: 3950S-3956S.

3. Whaley S, Sigman M, Neumann C, Bwibo N, Guthrie D, Weiss RE, Alber S and SP Murphy Impact of dietary intervention on the cognitive development of Kenyan school children. J. Nutr. 2003; 133: 3965S-3971S.

4. Pachón H, Simondon KB, Fall ST, Menon P, Ruel MT, Hotz C, CreedKanashiro H, Arce B, Domínguez MR, Frongillo EA, and DL Brown Constraints on the delivery of animal-source foods to infants and young children: Case studies from five countries. Food Nutr. Bull. 2007; 28: 215229.

5. Millman SR, Messer E and LF DeRose Who's hungry? And How Do We Know? Food Shortage, Poverty and Deprivation. United Nations University Press, New York. 1998: Chapter 5.

6. Gittlesohn J, Thapa M and LT Landman Cultural factors, caloric intake and micronutrient sufficiency in rural Nepali Households. Soc. Sci. Med. 1997; 44: 1739-1749.

7. Gittelsohn $\mathbf{J}$ and AE Vastine Sociocultural and household factors impacting selection, allocation and consumption of animal source foods: Current knowledge and application. J. Nutr. 2003; 133: 4036S-4041S.

8. Colecraft EK, Marquis GS, Aryeetey R, Sakyi-Dawson O, Lartey A, Ahunu B, Canacoo E Butler LM, Reddy MB, Jensen HH and E HuffLonergan Constraints on the use of animal source foods for young children in Ghana: A participatory rapid appraisal approach. Ecol. Food Nutr. 2006; 4: 351-377.

9. Global Livestock CRSP Annual Report: Global Livestock CRSP 2006, University of California, Davis. 2006: 1-31.

10. Marquis GS, Vogel E, Colecraft EK and O Sakyi-Dawson A qualitative assessment of support programs for caregivers' income generation activities in Ghana. Research Brief 08-01-ENAM 2008; Global Livestock Collaborative Research Support Program (GL-CRSP), University of California, Davis. 
11. Colecraft EK Nutrition Education Flipchart: Improving Feeding Practices of Caregivers of 2-to-5 Years Old Children. Enhancing Child Nutrition through Animal Source Food Management (ENAM) Project, University of Ghana, Legon, 2008.

12. Colecraft EK, Marquis GS, Sakyi-Dawson O, Lartey A, Ahunu B, Butler LM, Jensen HH, Reddy MB, Lonergan E, and E Canacoo Purchased ready-to-eat foods are positively associated with children's animal source food intakes in rural Ghana.FASEB J. 2008 22:873.5.

13. Colecraft EK and D Amoah Community-based Entrepreneurial Education Flipchart: Strengthening Women's Entrepreneurial Skills. Enhancing Child Nutrition through Animal Source Food Management (ENAM) Project, University of Ghana, Legon, 2009.

14. Butler LM, Kobati GY, Anyidoho NA, Colecraft EK, Marquis GS, and O Sakyi-Dawson Microcredit-nutrition education link: A case study analysis of Ghanaian women's experiences with income generation and family care. AJFAND. 2012; 12: 5709-5724.

15. Lohman TG, Roche AF and R Martorell Anthropometric Standardization Reference Manual. Human Kinetics Books, Chicago, 1988.

16. Sakyi-Dawson O, Marquis GS, Lartey A, Colecraft EK, Ahunu B K, Butler LM, Jensen HH, Lonergan E, and W Quarmine Impact of Interventions on Caregivers' Nutrition Knowledge and Animal Source Food Intake in Young Children in Ghana. Research Brief 09-04-ENAM 2009; Global Livestock Collaborative Research Support Program (GL-CRSP), University of California, Davis.

17. Lartey A, Colecraft E, Marquis GS, Sakyi-Dawson O, and B Ahunu Nutrition Education with Microcredit Provided to Caregivers of Pre-school Children: Effect on Children's Animal Source Food Intake. Research Brief 0906-ENAM 2009; Global Livestock Collaborative Research support Program (GL-CRSP), University of California, Davis.

18. Leatherman DS and C Dunford Linking Microfinance to Reduce Poverty. Bull. World Health Organ. 2010; 88: 470-471.

19. Rosato M, Laverack G, Howard-Grabham L, Triphany $P$, Nair Nirmala N, Mwansambo C, Azad K, Morrison J, Bhutta Zulfigar, Perry H, Rifkin S, and A Costello Community participation: Lessons for maternal, newborn, and child health. The Lancet 2008; 372: 962-971.

20. Freedom from Hunger Impact of Credit with Education on Mothers and Their Young Children's Nutrition: Lower Pra Rural Bank Credit with Education Program in Ghana. 1998 Research paper No. 4. 
21. Anyidoho NA, Kobati G, Butler LM, Colecraft EK and O Sakyi-Dawson Using Case Studies to Understand Successful Entrepreneurship Among Ghanaian Women. Research Brief 09-01-ENAM 2009; Global Livestock Collaborative Research Support Program (GL-CRSP), University California, Davis. 